\title{
Моделирование спектроскопии характеристических потерь энергии электронами и катодолюминесценции методом дискретных диполей
}

\author{
А.А. Кичигин \\ Институт химической кинетики и горения СО РАН \\ Новосибирский государственный университет \\ *E-mail: alkichigin@gmail.com
}

DOI: 10.31868/RFL2020.222-223

Спектроскопия характеристических потерь энергии электронами (electronenergy-loss spectroscopy - EELS) является экспериментальной техникой расширение для стандартного электронного микроскопа. На область расположения наночастицы направлен пучок релятивистских электронов, и измеряются потери кинетической энергии этими электронами после взаимодействия с частицей, для каждого положения луча строится спектр потерь (спектр EELS). При облучении быстрыми электронами частица начинает светиться - это явление называется катодолюминесценцией (cathodoluminescence - CL). Интенсивность излучения от частицы также измеряется и строится спектр CL. EELS и CL широко используется для исследования плазмонных наночастиц, поскольку те демонстрируют уникальные оптические свойства, вызванные наличием локализованных плазмонных резонансов (ЛПР). Использование электронного пучка позволяет обнаружить ЛПР на сечении частицы с погрешностью менее 1 нм, что является недостижимым результатом для оптических методов из-за дифракционного предела. Метод дискретных диполей (discrete dipole approximation - DDA) является численно точным методом для моделирования взаимодействия э/м волн с частицами произвольной формы и внутренней структуры. Он основан на объемном интегральном уравнении (ОИУ) в частотной области [1].

Данная работа посвящена реализации моделирования EELS и CL при помощи DDA. Все теоретические выводы основаны на решении ОИУ через тензор Грина. В частности, выражения для напряженности электрического поля релятивистского электрона получены интегралом с тензором Грина вдоль траектории электрона. В том числе было получено выражение для потерь энергии электроном, движущимся быстрее скорости света в непоглощающей среде (излучение Вавилова-Черенкова), которое совпало с известной формулой ФранкаТамма. Далее было получено общее выражение для дополнительных потерь энергии (из-за взаимодействия с частицей). Это общее выражение задается интегралом по объему частицы (очень удобно вычислять в DDA) и верно не только для нахождения частицы в вакууме, но и в произвольной (даже поглощающей) среде, что является новым результатом. Моделирование EELS и CL согласно полученным формулам реализовано в открытом ПО ADDA [2]. Ha Рис. 1 приведено сравнение результатов моделирования спектров с точным решением. 


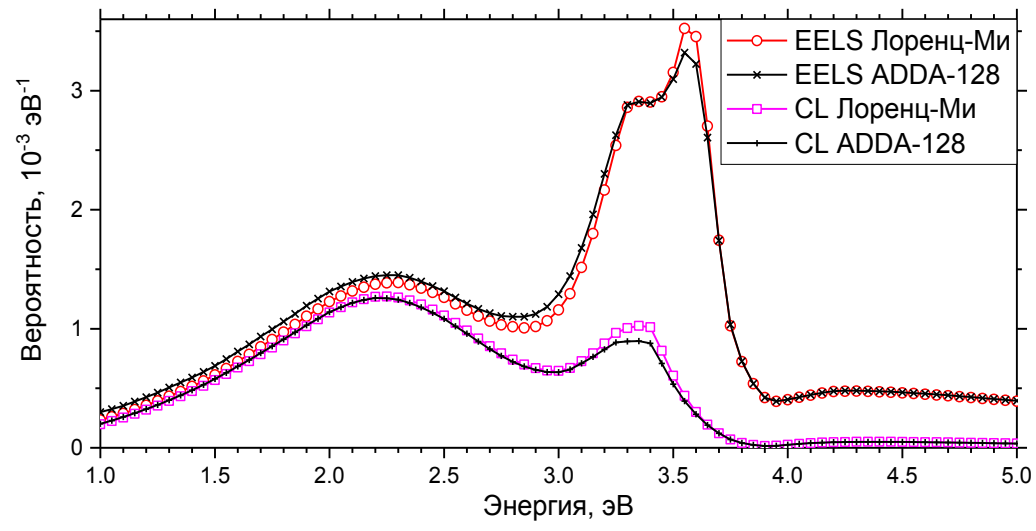

Рис. 1. Спектры EELS и CL, полученные точным решением по теории Лоренца-Ми и моделированием в ADDA (решетка по 128 диполей на ось). Электрон с энергией 100 кэВ пролетает в вакууме в 100 нм от центра серебряного шара радиусом 75 нм.

На Рис. 2 по результатам моделирования визуализирован ЛПР.



Рис. 2. Моделирование EELS в ADDA (решетка по 60 диполей на ось). Серебряная призма толщиной 5 нм (в основании треугольник с высотой 10 нм) сканируется электроном с энергией 100 кэВ на резонансной для этой призмы энергии 2.633 эВ.

\section{Литература}

[1] M.A. Yurkin and M.I. Mishchenko, Phys. Rev. A 97, 043824 (2018)

[2] M.A. Yurkin and A.G. Hoekstra, JQSRT 112, 2234-2247 (2011)

Научный руководитель - канд. физ.-мат. наук М. А. Юркин 